\title{
A Study on the Energy Price Reform Based on Energy Saving and Emission Reduction
}

\author{
Haiwen Long ${ }^{1, a}$ \\ ${ }^{1}$ Oxbridge College, Kunming University of Science and Technology, Kunming City, Yunnan Province, \\ 650106, China \\ ${ }^{1}$ School of Economics, Yunnan University, Kunming City, Yunnan Province, 650091, China
}

Keywords: Energy price; Environmental protection; Energy saving; Consumption

\begin{abstract}
The reasonable energy price formation mechanism promotes resource conservation and environmental protection, and improves sustainable economic development. As an important means of regulating energy demand, the energy price plays an important role in promoting the process of energy saving and emission reduction. Based on the learning and practical experience, this paper firstly analyzed the mechanism of energy price reform on energy saving and emission reduction, and then studied the main problems existing in the process of China's energy price reform, and finally put forward the path of energy price reform based on energy saving and emission reduction. structure
\end{abstract}

\section{Introduction}

Since the reform and opening up, China's economy has maintained rapid growth, and GDP has been ranked second in the world with great achievements. But at the same time, the contradiction between resources and environment has become increasingly prominent, and has restricted the future development of China's economy. Energy is an important basis for the development of the national economy, and has a very close relationship with other industries; however, energy prices are one of the most critical factors affecting energy consumption. The establishment of a reasonable energy price formation mechanism by pushing the reform of energy prices will not only directly affect the total energy consumption in various fields, but also bring about changes in energy use efficiency, so as to effectively promote energy conservation and emission reduction in various fields.

\section{Function Mechanism of Energy Price Reform on Energy Saving and Emission Reduction}

Optimize the energy structure through changes in energy price parity. The rise of traditional fossil energy prices will cause the change of price parity relations between different energy price. We will encourage the main energy consumption for the development and utilization of clean energy and other energy sources. Changes in energy structure, especially the rising proportion of clean energy, will inevitably reduce the pressure on energy consumption and emissions.

Improve energy efficiency through technological progress. The rising energy prices will inevitably lead to the improvement of energy utilization costs, forcing the use of energy to reduce costs; it also accelerates the pace of technological innovation and improves the efficiency of energy utilization. in other words, it will promote energy conservation and emission reduction through technology optimization of energy consumption and other factors of production.

The adjustment of industrial structure can realize the efficiency of energy allocation. With the increase of energy price, the cost of high energy consuming industry will rise, and it will be in a disadvantageous position in competition with other industries. High energy consuming enterprises will be further compressed space, and some high energy consuming enterprises that unable to adapt to the cost increase will be eliminated. The energy consumed by some high energy consuming industries will be released, which will lead to the reallocation of energy among different 
industries and promote the realization of energy conservation and emission reduction targets.

\section{The Main Problems Existing in the Process of Energy Price Reform in China}

Irrational energy pricing issues are highlighted. Because of the existence of energy subsidy policy in China and the great contrast between energy price and resource scarcity, most of China's energy prices have been implemented by the government. Government pricing does not fully reflect the relationship between supply and demand, nor does it take into account the cost of environmental pollution restoration and the depreciation of infrastructure. The too low energy price can not reflect the true value of energy, and the price relations between various energy sources is not reasonable.

The current situation of monopoly and competition is not conducive to price reform. At present, a large number of monopoly and competition coexist in the energy field, such as coal industry. Most of the coal enterprises in China are strong and large coal enterprises, but small coal enterprises are also relatively large. These small coal enterprises can not compete with large coal enterprises. Oil, gas, electricity and other industries also have such problem. In the field of energy, low level of competition was caused by the monopoly of large enterprises. Therefore, small and medium-sized enterprises can only survive in the cracks. This phenomenon will continue to exist in a certain period of time, and seriously hinder the reform process of China's energy prices.

The game dilemma between government and energy enterprises. At present, the Chinese government considers the environment, resources, cost and other factors, so that to launch the energy-saving emission reduction policies. For energy enterprises, with the deepening of energy-saving emission reduction policy, they will inevitably increase the production costs of enterprises, which can not be rewarded in the short term. To prevent further inflation brought about negative impact on economic growth, government does not want to put energy price control to the market, which will cause the game between the government and enterprises of energy transformation.

\section{Energy Price Reform Path Based on Energy Saving and Emission Reduction}

Improve the energy consumption structure and formulate the correct energy development strategy. Firstly, we should speed up technological innovation and optimize the consumption structure. Energy companies must accelerate technological innovation, improve energy efficiency, and constantly develop new energy sources to optimize the structure of energy consumption. On the one hand, we must strengthen the development and utilization of renewable resources, and continue to develop new technologies to reduce the development and utilization costs of wind energy, water power and nuclear energy; in addition, we need to reduce the proportion of coal consumption of petroleum energy and optimize energy consumption structure. On the other hand, we should pay attention to clean technology research and development in the process of new energy development; moreover, we should focus on improving the clean coal technology and the utilization efficiency of oil and natural gas. Only by constantly excavating new energy sources and improving the efficiency of traditional energy use, can we optimize the energy consumption structure of our country.

Secondly, we should formulate a correct energy development strategy and strengthen the regulation of energy consumption structure. We will continue to implement energy conservation and emission reduction policies and improve energy efficiency. We should formulate a correct strategy for energy development and constantly readjust the structure of energy products with innovation. To improve energy efficiency, we should ensure the coordinated development of the ecological environment. China's dependence on foreign energy is particularly large, especially in the field of oil and energy. In the event of an oil supply chain disruption, China will be in great danger. We should actively establish an efficient oil reserve system, reduce our dependence on foreign energy, and ensure national energy security. In addition, China lacks market competition in the energy sector, so as to establish and improve market access mechanism in the energy sector as soon as possible and to play the role of market competition in optimizing energy allocation. We should 
improve the energy regulatory system and establish an early warning mechanism for energy consumption, so as to promote the smooth operation of the energy market.

Improve the energy coordination management mechanism to ensure the coordinated reform of energy price reform. China's energy industry is lack of unified management and coordination, which makes the price reform in various fields of energy system lack coordination and relevance. As for the Europe and the United States, most of them are setting up the independent and high-quality government institutions in energy security and development fields. For example, the United States, the United Kingdom, France have set up the department of energy, which is responsible for unified planning, management and coordination in all fields of energy. In order to promote China's energy price reform as a whole, we need to establish a higher level macro management department, which is responsible for formulating energy strategies, planning and policies, regulating total energy balance and ensuring energy security. We need to implement a unified planning and management of the reform and development of various fields of energy, and truly build a coordination mechanism in all areas of energy. At present, under the leadership of the National Energy Council, we should continue to strengthen the functions of the national energy board and integrate some of the major functions of other ministries in the energy sector. When the conditions are basically mature, we need to set up the department of energy.

Strengthen the supervision mechanism for energy prices and build a fair competitive market environment. On the one hand, we should strengthen the construction of supervision system. To improve construction of energy management institutions at the same time with the spirit of "political prison separation" principle, we should also establish the professional energy regulatory agencies, which is mainly responsible for the order and standardized operation of the energy market. On the other hand, we should actively develop the reasonable energy price supervision system. First, we should establish and improve the energy industry and enterprise information disclosure system. According to the standard format, we should report regularly on its operating conditions. Secondly, we should establish and improve the price hearing system, and give full play to the role of public oversight. The third is that we should increase penalties for violations of prices, so that to crack down on a number of violations.

Accurately grasp the timing and mode of the price reform and reduce the impact of the reform on the economic operation and the people's livelihood. The timing and mode of energy price reform are crucial to the effectiveness of the reform. First, the timing of price reform should be rationally chosen. On the one hand, we should actively promote the reform in the situation of energy industry running being relatively better, so that the difficulty, cost and affect social stability of the reform are smaller. On the other hand, we should promote the reform of the price down-time window. We should avoid the situation of inflation driven by triggering cost and affecting the smooth operation of the economy caused by rising prices and the reform pushing up the price cycle. Second, we should try our best to implement the step pricing method for the user terminal price. We should make full use of the method of tranche pricing to set the capacity and price of the first gear reasonably, so that energy demand that satisfies people's basic life will not rise too fast. Third, we should improve the price subsidy system for low-income groups. We should formulate and improve a special subsidy system for low-income groups with low affordability and related public welfare industries, so as to offset the possible adverse effects of energy price reform, such as increasing the price of residents' electricity, gas and so on. It needs to be emphasized that the system design should let subsidies really fall to the people who need subsidies, and avoid the phenomenon that most of the beneficiaries may not be the real target group.

\section{Summary}

This paper studied the relationship between energy price reform and energy saving and emission reduction, analyzed the main problems of China's energy price reform, and put forward the reform scheme is feasible. The results of this research are clear as follows: Energy prices can regulate energy consumption; the study of energy price reform can effectively make use of China's manpower, material and financial resources to optimize the allocation of energy, so as to contribute 
to energy conservation and emission reduction in China.

\section{Acknowledgements}

Scientific research foundation project of Yunnan Province Office of Education(2016ZDX239).

\section{References}

[1] Li Na. China's Energy Consumption Structure and Energy Price Reform[J]. Price Monthly, 2015, (04): 1-3.

[2] Bai Mei. Deepening the Reform of Energy Prices: Laws, Goals and Paths[J]. Price Theory and Practice, 2014, (04): 5-9.

[3] Xiao Xingzhi. China's Practice and Market Reform of Energy Pricing Regulation[J]. Price Theory and Practice, 2014, (01): 23-27.

[4] Shi Dan. Characteristics, Difficulties and Key Points of Current Energy Price Reform[J]. Price Theory and Practice, 2013, (01): 18-20.

[5] Zhao Meitian. The Study on Energy Price Reform Based on Safety[J]. China Coal, 2011 (05): 32-36.

[6] Wang Jun. Research on the Mechanism of Energy Price Reform in China[J]. Economic Issues, 2010, (10): 43-47.

[7] Luo Hanwu, Li Fang. The Reform of Energy Prices and Subsidies[J]. Economic Survey, 2009, (02): 124-127. 